\title{
Rheological Behavior of Composites Based on Carbon Fibers Recycled from Aircraft Waste
}

\author{
Lucie Marcaníková, Berenika Hausnerová and Takeshi Kitano \\ Polymer Centre, Faculty of Technology, Tomas Bata University in Zlin TGM 275, 76272 Zlin, \\ Czech Republic
}

\begin{abstract}
Rheological investigation of composite materials prepared from the recycled aircraft waste materials based on thermoset (epoxy/resin) matrix and long carbon fibers (CF) is presented with the aim of their utilization in consumer industry applications. The carbon fibers recovered via thermal process of pyrolysis were cut into about $150 \mu \mathrm{m}$ length and melt mixed with thermoplastic matrices based on polypropylene (PP) and polyamide 6 (PA) and various modifiers - ethylene-ethyl acrylate-maleic anhydride (E-EA-MAH), polypropylene grafted maleic anhydride (PP-g-MA) and poly(styrene)-block-poly(ethylene-co-but-1-ene)-blockpoly(styrene) (SEBS). Rheological, electrical, mechanical, thermal and morphological results revealed the composites of recycled CF and PP/PP-g-MA as well as PA/E-EA-MAH to be the most promising candidates for new applications.
\end{abstract}

Keywords: Carbon fiber, Recycling, Rheological properties, Mechanical properties. PACS: $81.05 . \mathrm{Qk}, 81.70 . \mathrm{Bt}, 83.85 . \mathrm{Cg}$

\section{INTRODUCTION}

Utilization of carbon fibers (CF) in the production of polymer composites for high-technology applications is developed rapidly due to their excellent mechanical, thermal and electrical properties. Short carbon fibers, in particular, posses the additional advantage to be easily processed on high-production conventional techniques such as extrusion and injection molding.

As a processing route of recycling of composite material, pyrolysis has the advantage that all of the products can be potentially recovered and reused; polymeric components decompose to oil and gas products, and reinforcing fibers are recovered with a minimum degradation enabling their frequent employment in the composites production [1].

Recycled carbon fibers reinforced thermoplastics and thermosets have a benefit of lower cost at substantially same properties as obtained with virgin carbon fibers based composites [2]. Recently, Kouparitsas et al. [3] used a grinding and sifting procedure to recover carbon fibers from an epoxy/CF composite, which were then melt mixed $(20 \mathrm{wt} \%)$ with ionomer $\left(\operatorname{Surlyn}^{\circledR} 8528\right)$. The elastic modulus and tensile strength of the recycled $\mathrm{CF}$ filled ionomer decreased slightly and the elongation at break increased when compared with virgin $\mathrm{CF}$ filled ionomer at the same loading. 
Mechanical as well as electrical measurements followed by morphological study of dispersion of polyethylene (PE) matrix filled with recycled $\mathrm{CF}$ obtained via thermochemical process from epoxy/CF composites used in Formula 1 motor racing cars were presented by McNally et al. [2]. The tensile mechanical properties such as Young's modulus of PE increased from $258 \mathrm{MPa}(0 \mathrm{wt} \%)$ to $724 \mathrm{MPa}(30 \mathrm{wt} \%)$, and accordingly the tensile stress increased from $17.5 \mathrm{MPa}$ to $22.3 \mathrm{MPa}$ upon $\mathrm{CF}$ reinforcement. The percolation threshold was determined at $7 \mathrm{wt} \%(500 \mu \mathrm{m}$ film $)$ and $15 \mathrm{wt} \%$ (3 $\mathrm{mm}$ thick plaque).

Markov et al. [4] described the preparation, mechanical properties, and electrical conductivity of recycled carbon fiber (between 10 and $20 \mathrm{wt} \%$ ) filled glass fiber (GF) reinforced high-density polyethylene (HDPE). The carbon fibers were reclaimed from prepregs using a pyrolysis technique at $700^{\circ} \mathrm{C}$, purified, and then laminated via first impregnation GF rovings with $\mathrm{HDPE} / \mathrm{CF}$ suspension that was prepared using sonication assisted solution mixing. The electrical conductivity of the GF/HDPE matrix was increased upon addition of $\mathrm{CF}$ and the percolation threshold appeared at about $15 \mathrm{wt} \%$ filling of CF.

This work focuses on a selection of appropriate polymer matrices for composites based on carbon fibers recycled from the aircraft waste. The rheological (viscoelastic and steady shear) properties as well as electrical behavior in terms of AC and DC conductivities and dielectric properties, thermal properties and morphology were investigated in order to select the composite appropriate for further reutilization.

\section{EXPERIMENTAL}

\section{Materials}

The carbon fibers, which were acquired from the composites used in aircraft production based on epoxy resin, were recycled with a recently developed technique in the Aeronautical Research and Test Institute, Prague, Czech Republic on the equipment called Experimental Test System for Fibrous Thermosetting Composites Breakdown at $550^{\circ} \mathrm{C}$ in a non-inert atmosphere. The recycled long carbon fibers were chopped into strands $7 \mu \mathrm{m}$ in diameter and $150 \mu \mathrm{m}$ in length [5]. In the Figure 1 recycled carbon fiber is clearly seen to contain a residue of a resin matrix in terms of hydroxyl $(-\mathrm{OH})$, carboxyl $(-\mathrm{COOH})$ and carbonyl $(-\mathrm{C}=\mathrm{O})$ groups.

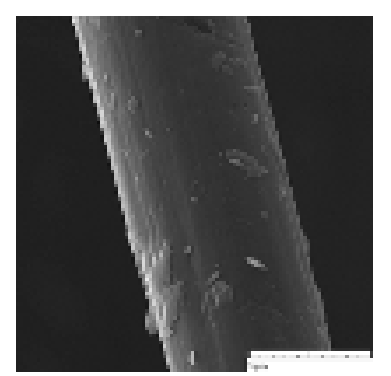

FIGURE 1. SEM micrograph of recycled carbon fiber. 
In this study pelletized polypropylene - PP (Tipplen H284F, TVK, Hungary - density $0.90 \mathrm{~g} / \mathrm{cm}^{3}$ ) and polyamide 6 - PA (Ultramid ${ }^{\circledR}$ B40LN, BASF, Germany - density $1.13 \mathrm{~g} / \mathrm{cm}^{3}$ ) served as matrix polymers.

Three types of modifiers were used: poly(styrene)-block-poly(ethylene-co-but-1ene)-block-poly(styrene) - SEBS (Tuftec ${ }^{\mathrm{TM}} \mathrm{H} 1062$, Asahi Kasei, Corp., UK), ethylene-ethyl acrylate-maleic anhydride - E-EA-MAH (Lotader ${ }^{\mathbb{B}} 8200$, Atofina, France) and polypropylene grafted maleic anhydride - PP-g-MA (Tabond 5007, Silon a.s., Czech Republic).

\section{Preparation of Composites}

Firstly, polypropylene (PP) and polyamide 6 (PA) matrices were modified as shown in the Table 1 and described below.

TABLE 1. Composition of matrices.

\begin{tabular}{lcc}
\hline Material code & Polymer (wt\%) & Modifier (wt\%) \\
\hline PP & $100 \mathrm{PP}$ & - \\
PP-5E & $95 \mathrm{PP}$ & 5 E-EA-MAH \\
PP-10E & $90 \mathrm{PP}$ & 10 E-EA-MAH \\
PP-10S & $90 \mathrm{PP}$ & 10 SEBS \\
PP-5G & $95 \mathrm{PP}$ & 5 PP-g-MA \\
PA & $100 \mathrm{PA}$ & - \\
PA-5E & $95 \mathrm{PA}$ & 5 E-EA-MAH \\
\hline
\end{tabular}

Weighted amounts of dried matrices and chopped strands of carbon fibers (for composition see the Table 2) were mixed thoroughly in a twin-screw extruder (Twin Screw Compounder TSC 42/6, Brabender GmbH \& Co. KG, Germany). Extrusion was performed by counter rotating screws with axial grooves at screw speed of $30 \mathrm{rpm}$. Screw diameter and length were $41.8 \mathrm{~mm}$ and $250.8 \mathrm{~mm}$, respectively. The temperatures in the compression, melting and mixing zones were set to 150,180 and $210^{\circ} \mathrm{C}$, respectively, for PP based composites, and 170,200 and $240^{\circ} \mathrm{C}$, respectively, for PA based mixtures. In order to obtain a well-dispersed structure, the materials were extruded through the die two times. The extrudates were then cut into $3 \mathrm{~mm}$ long pellets from which the testing samples were prepared via compression molding on a laboratory press for $3 \mathrm{~min}$ at $210^{\circ} \mathrm{C}$ for polypropylene and $230^{\circ} \mathrm{C}$ for polyamide based composites. Obtained testing specimens were $1 \mathrm{~mm}$ thick with dimensions $(125 \times 125) \mathrm{mm}$.

TABLE 2. Carbon fiber (CF) loading in thermoplastic matrices.

\begin{tabular}{lcc}
\hline Material code & Matrix $(\mathbf{w t} \%)$ & Carbon fiber $\mathbf{( w t} \%)$ \\
\hline $\mathrm{PP} / \mathrm{CF}$ & $100,95,90,85,80$ & $0,5,10,15,20$ \\
$\mathrm{PP}-5 \mathrm{E} / \mathrm{CF}$ & 100,90 & 0,10 \\
$\mathrm{PP}-10 \mathrm{E} / \mathrm{CF}$ & 100,85 & 0,15 \\
$\mathrm{PP}-10 \mathrm{~S} / \mathrm{CF}$ & 100,85 & 0,15 \\
$\mathrm{PP}-5 \mathrm{G} / \mathrm{CF}$ & $100,90,85$ & $0,10,15$ \\
$\mathrm{PA} / \mathrm{CF}$ & 100,90 & 0,10 \\
$\mathrm{PA}-5 \mathrm{E} / \mathrm{CF}$ & 100,90 & 0,10 \\
\hline
\end{tabular}


The samples for testing of mechanical properties were prepared from the pellets via injection molding on injection machine Ergotech 50-200 NC4 (DEMAG, Germany). The conditions for processing of PP and PA based composites are summarized in the Table 3.

TABLE 3. Conditions of injection molding of composites.

\begin{tabular}{lcc}
\hline & PP based material & PA based material \\
\hline mould temperature $\left({ }^{\circ} \mathrm{C}\right)$ & 50 & 75 \\
nozzle temperature $\left({ }^{\circ} \mathrm{C}\right)$ & 230 & 270 \\
metering zone $\left({ }^{\circ} \mathrm{C}\right)$ & 220 & 260 \\
transition zone $\left({ }^{\circ} \mathrm{C}\right)$ & 190 & 240 \\
feed zone $\left({ }^{\circ} \mathrm{C}\right)$ & 50 & 50 \\
injection pressure $(\mathrm{MPa})$ & 70 & 80 \\
injection rate $(\mathrm{mm} / \mathrm{s})$ & 50 & 40 \\
holding pressure $(\mathrm{MPa})$ & 50 & 35 \\
holding pressure time $(\mathrm{s})$ & 30 & 15 \\
cooling time $(\mathrm{s})$ & 20 & 10 \\
\hline
\end{tabular}

\section{Fiber-length and Fiber-length Distribution}

The fiber-length and its distribution of the $\mathrm{PP} / \mathrm{CF}$ composites were analyzed by an ordinary method - burning off matrix polymer in a muffle furnace at $450^{\circ} \mathrm{C}$ for $5 \mathrm{~h}$. The lengths of 800 fibers were measured carefully on magnified photographs. Number-average fiber-length $l_{\mathrm{n}}(\mu \mathrm{m})$ was calculated [6].

It was found (Table 4) that the fiber-length changes negligibly with increasing amount of $\mathrm{CF}$ in the composites. The representative fiber-length distribution revealed from the data obtained for $10 \mathrm{wt} \% \mathrm{PP} / \mathrm{CF}$ composite is depicted in the Figure 2.

TABLE 4. Fiber-length degradation during composites' preparation.

\begin{tabular}{lcc}
\hline Carbon fiber (wt\%) & Number-average fiber-length $(\boldsymbol{\mu m})$ & Aspect ratio $(-)$ \\
\hline 5 & 147.4 & 21.1 \\
10 & 144.6 & 20.7 \\
15 & 143.7 & 20.5 \\
20 & 142.6 & 20.4 \\
\hline
\end{tabular}

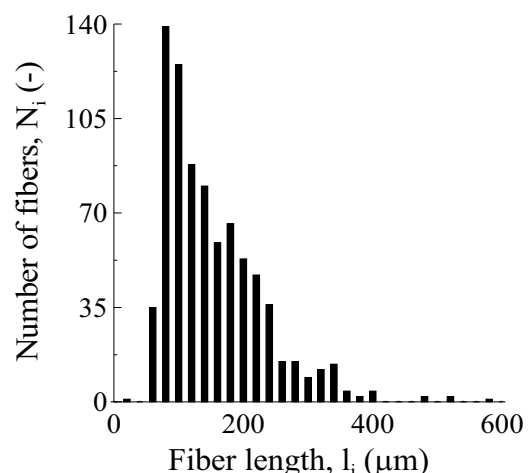

FIGURE 2. Fiber-length distribution of $10 \mathrm{wt} \%$ carbon fiber filled polypropylene. 


\section{Thermal Analysis}

The thermal behavior of the samples was determined on Pyris 1 DSC (Perkin-Elmer, USA) in sealed aluminum pans under a nitrogen atmosphere. Calibration was achieved with indium. The samples were preheated at a heating rate of $10^{\circ} \mathrm{C} / \mathrm{min}$ up to $250^{\circ} \mathrm{C}$ and maintained there for $5 \mathrm{~min}$ for the removal of any effects of thermal history. Subsequently, the samples were cooled down to $100^{\circ} \mathrm{C}$ at a cooling rate of $10^{\circ} \mathrm{C} / \mathrm{min}$ to obtain crystallization temperature $\left(T_{\mathrm{c}}\right)$. Melting peak temperatures $\left(T_{\mathrm{m}}\right)$ were achieved from the second heating (up to $250^{\circ} \mathrm{C}, 10^{\circ} \mathrm{C} / \mathrm{min}$ ). The average weight of samples was $7 \mathrm{mg}$.

As can be seen from the Table 5 , modifiers slightly decrease both $T_{\mathrm{m}}$ and $T_{\mathrm{c}}$. Further, upon addition of $\mathrm{CF}$, there are not pronounced shifts in melting points, while $T_{\mathrm{c}}$ of PP based composites changed significantly. Pronounced decays in $T_{\mathrm{c}}$ of PP based composites result from the $\mathrm{CF}$ playing a role of heterogeneous nucleation agent.

TABLE 5. Effect of modifiers and carbon fiber (10 wt\%) on melting $\left(T_{\mathrm{m}}\right)$ and crystallization $\left(T_{\mathrm{c}}\right)$ temperatures of polypropylene (PP) and polyamide $6(\mathrm{PA})$ matrices.

\begin{tabular}{lcccc}
\hline & \multicolumn{3}{c}{$\mathbf{0 ~ w t} \% \mathbf{C F}$} & \multicolumn{2}{c}{$\mathbf{1 0} \mathbf{~ w t} \% \mathbf{C F}$} \\
\hline & $\boldsymbol{T}_{\mathbf{m}}\left({ }^{\circ} \mathbf{C}\right)$ & $\boldsymbol{T}_{\mathbf{c}}\left({ }^{\circ} \mathbf{C}\right)$ & $\boldsymbol{T}_{\mathbf{m}}\left({ }^{\circ} \mathbf{C}\right)$ & $\boldsymbol{T}_{\mathbf{c}}\left({ }^{\circ} \mathbf{C}\right)$ \\
\hline PP & 161.7 & 112.0 & 161.1 & 122.2 \\
PP-5E & 159.0 & 109.3 & 160.3 & 120.7 \\
PP-5G & 158.1 & 109.9 & 161.1 & 121.9 \\
PA & 216.1 & 189.5 & 215.2 & 188.7 \\
PA-5E & 214.8 & 188.4 & 214.6 & 188.4 \\
\hline
\end{tabular}

\section{Morphology}

The morphology of composites was investigated with scanning electron microscopy (SEM) using a Vega II (Tescan s.r.o., Czech Republic) instrument operated at $10 \mathrm{kV}$. All samples were coated with a thin layer of gold using a polaron sputtering apparatus.

\section{Rheological Properties}

The test specimens for rheological measurements $(1 \mathrm{~mm}$ thick) were cut from compression molded plates in the shape of a circle with a $25 \mathrm{~mm}$ diameter. The dynamic properties $\left(G^{*}, \eta^{*}\right)$ were measured within linear viscoelastic region at constant strain of $1 \%$ on a rotational rheometer ARES (Rheometric Scientific Co., Ltd., USA) with parallel plates radius $25 \mathrm{~mm}$, the angular frequency $\omega$ set in the range from 0.01 to $100 \mathrm{rad} / \mathrm{s}$, temperatures 190,210 and $230^{\circ} \mathrm{C}$ for PP and 230,240 and $250^{\circ} \mathrm{C}$ for PA under nitrogen atmosphere to prevent thermo-oxidative degradation.

Steady shear flow properties at high shear rates were obtained from a capillary rheometer Göttfert Rheograph 2001 (Göttfert Werkstoff-Prüfmaschinen GmbH, Germany) at temperatures 190 and $210^{\circ} \mathrm{C}$ for PP and at 240 and $250^{\circ} \mathrm{C}$ for PA. The length-to-diameter $(L / D)$ ratio was $20 / 1$ and $0.12 / 1$ for long and orifice capillaries, respectively. Bagley and Rabinowitsch corrections were applied. 


\section{Electrical Properties}

The test specimens for electrical measurements were cut from compression molded square-shaped plates with required dimension of $(20 \times 20 \times 1) \mathrm{mm}$. Hioki $3522-50$ LCR HiTester (HIOKI E.E. Corporation, Japan) capable to measure frequency-dependent conductivity and dielectric characteristics in terms of the $\mathrm{AC}$ conductivity $\sigma_{\mathrm{AC}}$, relative permittivity $\varepsilon^{\prime}$ and dielectric loss factor $\tan \delta$ at low frequencies $\left(10^{2}-10^{5} \mathrm{~Hz}\right)$ was employed. Measurements of current/voltage characteristics in the applied DC field (DC conductivity $\sigma_{\mathrm{DC}}$ ) were carried out using a Keithley 6517A Programmable Electrometer (Keithley Instruments, Inc., USA), which is also utilized as a stabilized DC power source. Electrical measurements of the matrices and composites were performed at ambient laboratory temperature $\left(23 \pm 2^{\circ} \mathrm{C}\right)$, five samples of each material were tested and the average values were reported.

\section{Mechanical Properties}

The specimens were prepared according to standards: ISO 527, ISO 179 and ISO 178 , and measurements were performed at ambient temperature $\left(23 \pm 2^{\circ} \mathrm{C}\right)$ and constant humidity $(50 \pm 5 \%)$. Impact strength was measured on Zwick 5113 (Zwick $\mathrm{GmbH} \&$ Co. KG, Germany) instrument with a pendulum $15 \mathrm{~J}$ and $(10 \times 4 \times 60) \mathrm{mm}$ specimen with a flatwise position. Tensile and three-point bending tests were measured on universal testing machine Instron 8871 (Instron, UK). The tensile properties were tested with standard specimen 1A (ISO 527-1) at a speed of $20 \mathrm{~mm} / \mathrm{min}$. The three-point bending test was performed at a speed of $10 \mathrm{~mm} / \mathrm{min}$ on specimens having the same dimensions as for impact tests.

\section{RESULTS AND DISCUSSION}

Rheological investigation has proven to be a sensitive tool to study both processing properties and dispersion (phase structure) of filled polymers.

Firstly, the composites based on unmodified PP with different CF content varying from 5 to $20 \mathrm{wt} \%$ are discussed, Figure 3 . The effect of CF concentration on the viscoelastic properties becomes pronounced at the loading level above $10 \mathrm{wt} \%$. Upon this filling level the complex viscosity plateau regions (typical feature of a viscoelastic fluid) in the low frequency region become diminished due to rising particle-particle interactions.

Both storage and loss moduli are larger than obtained for the pure melt depicting composites' higher capacity to store/dissipate energy. Viscous properties in terms of loss modulus are about two orders of magnitude higher than storage (elastic) response to oscillatory flow. The effect of $\mathrm{CF}$ is more pronounced at lower angular frequencies.

Concerning capillary data (Figure 4) measured at high shear rates region, covering the real processing conditions, the following results were obtained. Empirical Cox-Merz rule, which should be generally valid for flexible molecules is obeyed for data of pure PP and its composites with $\mathrm{CF}$ up to $10 \mathrm{wt} \%$; with rising $\mathrm{CF}$ 
concentration the distinctions are increasingly perceptible - steady shear viscosity is lower than complex viscosity.

As expected, shear viscosity rises up with increasing fiber content, although at higher shear rates (above $100 \mathrm{~s}^{-1}$ ) the discrepancies diminish.

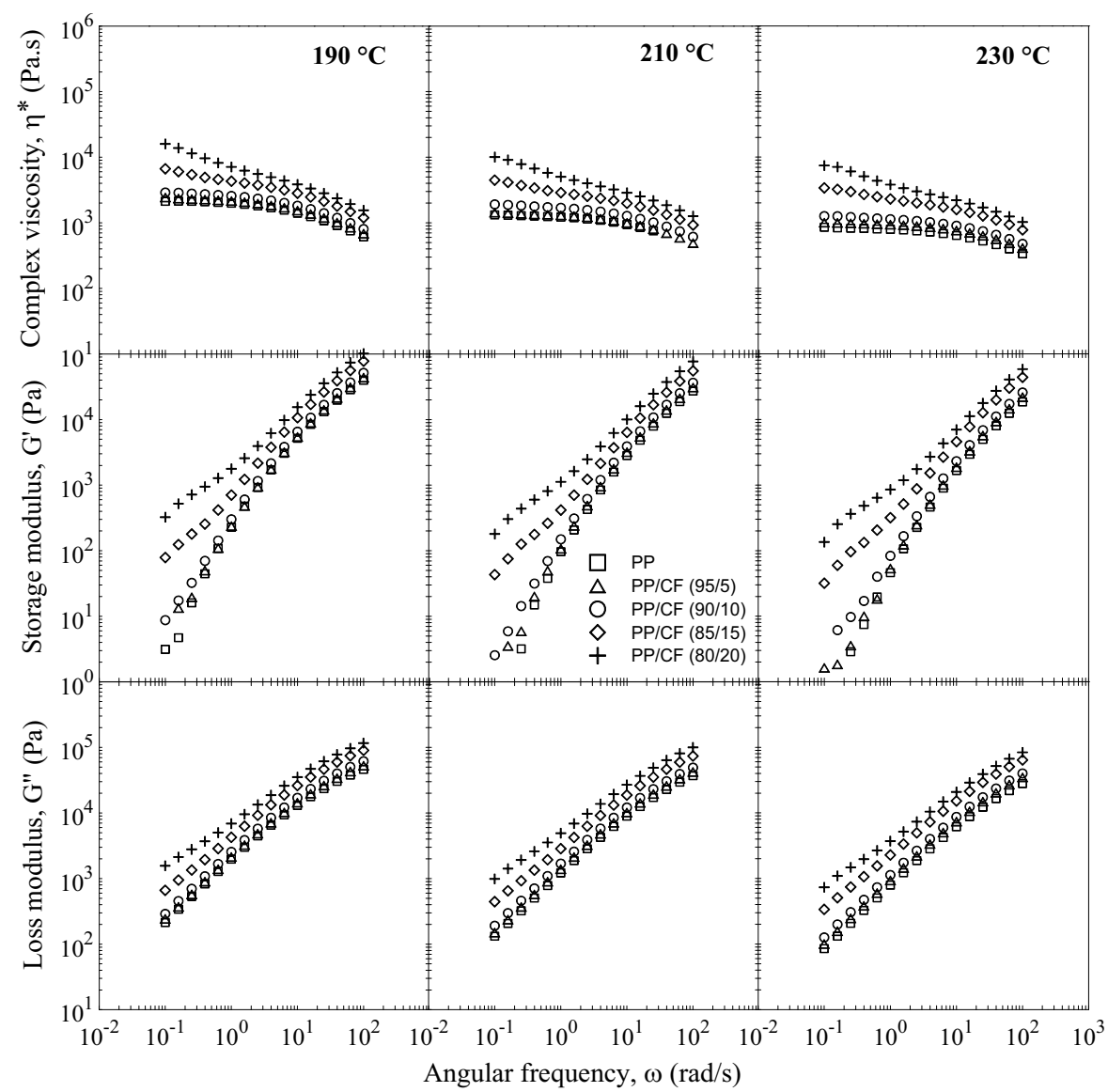

FIGURE 3. Viscoelastic properties as a function of angular frequency for pure and filled (5-20 wt $\%$ carbon fiber) polypropylene at three different temperatures.

In the next, polypropylene matrix was combined with various modifiers - SEBS, PP-g-MA and E-EA-MAH. It has been widely accepted [7] that PP modified with polypropylene grafted maleic anhydride (PP-g-MA) has enhanced adhesion to polar fillers, resulting in improved mechanical properties of the composites. PP-g-MA posses low molecular weight and high hardness, and thus should improve the mechanical properties of PP, and simultaneously reduce its melt viscosity, which is used especially for the coating applications [8]. 


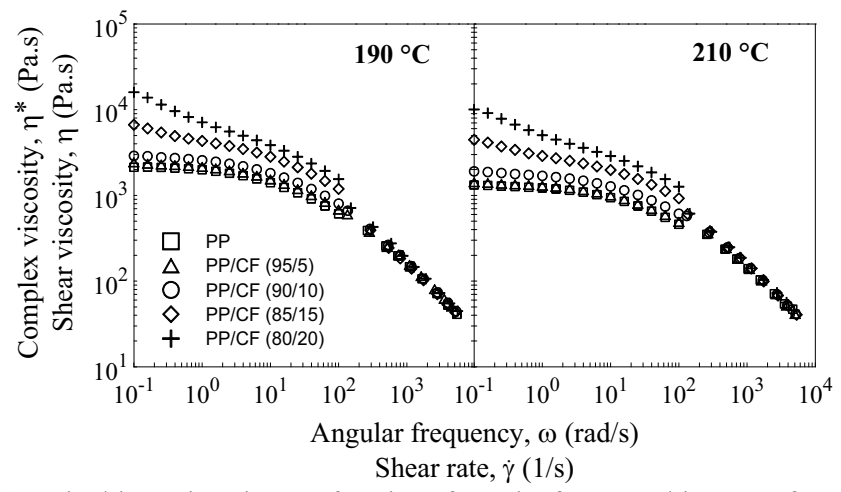

FIGURE 4. Complex/shear viscosity as a function of angular frequency/shear rate for pure and filled (5-20 wt \% carbon fiber) polypropylene at different temperatures.

The second modifier applied to PP matrix was terpolymer ethylene-ethyl acrylatemaleic anhydride (E-EA-MAH), utilized in applications where overcoming the tendency to brittleness at temperatures below glass temperature and low stiffness are important issues. This compatibilizer is used mainly to improve impact strength of PET blends [9] and PP mixtures [10], and advance dispersion of fibers/particles in polymer matrix, as well as to improve adhesion between matrix and fillers [11].

Finally, polypropylene in composites can be toughened by incorporating elastomer microparticles [12]; in our case $10 \mathrm{wt} \%$ SEBS - poly(styrene)-block-poly(ethene-cobut-1-ene)-block-poly(styrene) was tested. Interfacial tension and adhesion play essential role when SEBS is selected as compatibilizing and toughening agent, attaining an improvement of impact properties achieved by energy dissipation at interfaces of immiscible blends and composites. Generally, if molecular weight of block copolymer is high enough, it can act at both sides of the interface as an anchor; SEBS is usually used in blends, where one component shows a good compatibility with the olefinic block, and the other component has a good compatibility with the styrene blocks $[13,14]$.

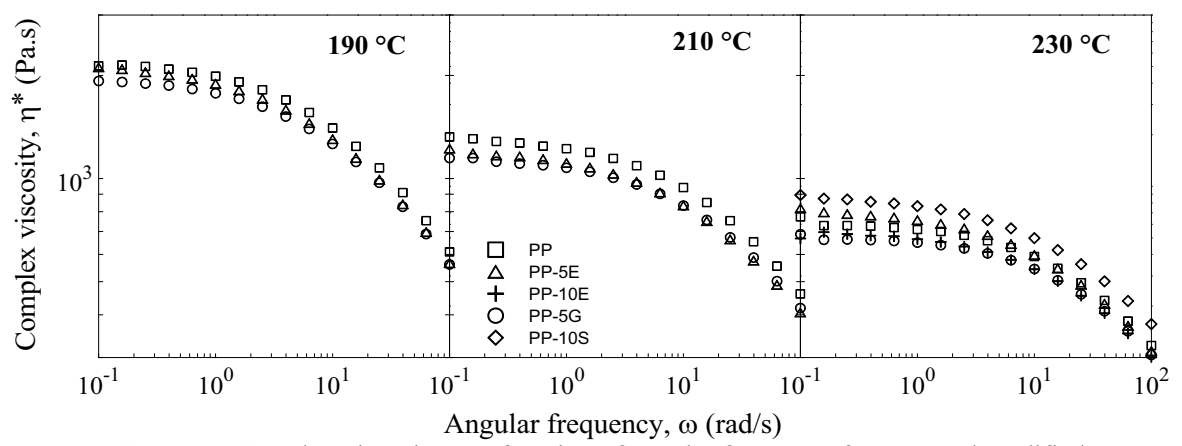

FIGURE 5. Complex viscosity as a function of angular frequency for pure and modified polypropylene at three different temperatures. 
The complex viscosity of all PP samples (pure and modified) show plateau at frequencies up to about $1 \mathrm{rad} / \mathrm{s}$, Figure 5 . The shear viscosity obtained from capillary rheometry reveals pseudoplastic manner of pure and modified PP, the differences in the particular matrices are almost not noticeable at high shear rates. At the highest temperature $\left(230^{\circ} \mathrm{C}\right)$ also $10 \mathrm{wt} \%$ modification of PP with SEBS and E-EA-MAH was examined and it has been found the same effect of $10 \mathrm{wt} \%$ of E-EA-MAH as obtained for $5 \mathrm{wt} \%$ of PP-g-MA, and viscosity increase for SEBS modified sample beyond viscosity of pure PP.

The effect of modification on rheological properties of $\mathrm{PP} / \mathrm{CF}$ composites has been studied on 10 and $15 \mathrm{wt} \%$ samples. For $15 \mathrm{wt} \% \mathrm{CF}$ composites (Figure 6), where the differences among particular modifiers are more evident, only maleic grafted sample (PP-5G/CF) shows lower viscoelastic functions than unmodified (PP/CF) material; modification with SEBS and E-EA-MAH both reveal higher viscosity level than for pure $\mathrm{PP} / \mathrm{CF}$. Figure 7 depicts a slight decrease of maleic grafted $10 \mathrm{wt} \%$ sample (PP-5G/CF), while other modified composites (in the figure represented by PP-5E/CF) showed the opposite effect, especially in the low angular frequency region.

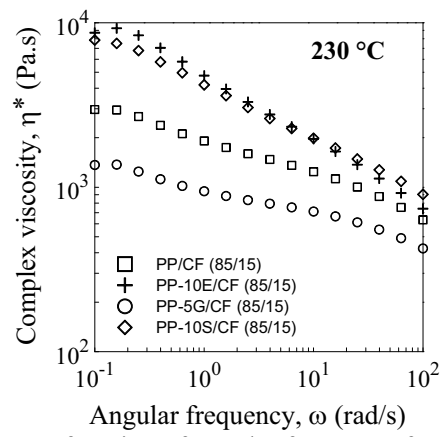

FIGURE 6. Complex viscosity as a function of angular frequency for $15 \mathrm{wt} \%$ carbon fiber filled pure and modified polypropylene at temperature $230^{\circ} \mathrm{C}$.

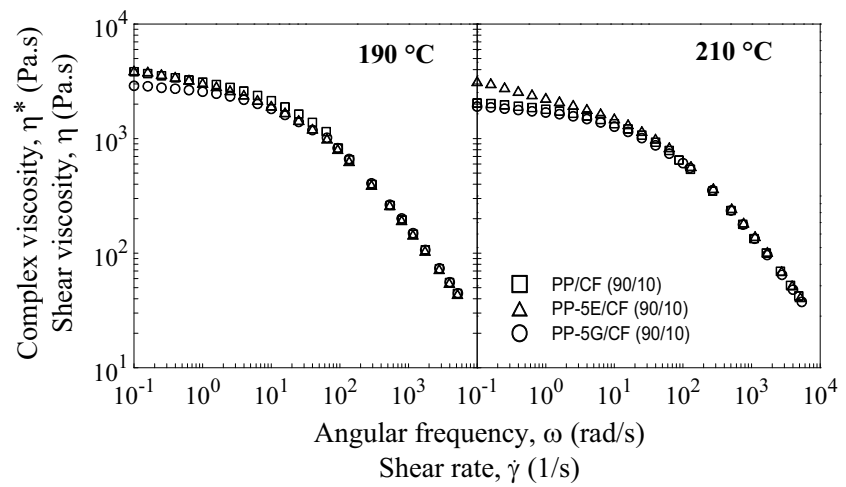

FIGURE 7. Complex/shear viscosity as a function of angular frequency/shear rate for $10 \mathrm{wt} \%$ carbon fiber filled pure and modified polypropylene at different temperatures. 
SEM study confirms presumption that non-polar polypropylene has a poor adhesion to recycled $\mathrm{CF}$ (Figure $8 \mathrm{a}$ ), which is subsequently improved after matrix modification as shown on example of PP-5G/CF composite, Figure $8 \mathrm{~b}$.

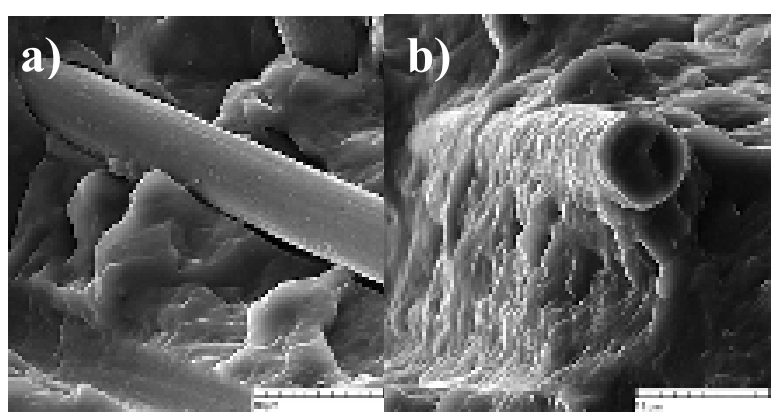

FIGURE 8. SEM micrographs of $10 \mathrm{wt} \%$ carbon fiber filled (a) unmodified and (b) PP-g-MA modified polypropylene.

As the differences in rheological behavior of the particular composites were rather ambiguous, the investigation was further supported by measurement of electrical properties. The measured AC conductivity of the unfilled samples increases with frequency in range $10^{-7}-10^{-11} \mathrm{~S} / \mathrm{m}$. The DC conductivity of PP based matrices is decreasing with the applied voltage; the most pronounced drops are depicted up to $20 \mathrm{~V}$, although the overall conductivity is in the orders of $10^{-11}-10^{-12} \mathrm{~S} / \mathrm{m}$. Conductivity increases with fiber content - at the $20 \mathrm{wt} \% \mathrm{CF}$ both $\sigma_{\mathrm{AC}}$ and $\sigma_{\mathrm{DC}}$ reach about $10^{-3} \mathrm{~S} / \mathrm{m}$.

The PP-5G/CF composite does not show a plateau region indicating AC conductivity, Figure 9. Furthermore, its AC conductivity is very low comparing to other materials tested. It implies that the PP-g-MA as a matrix bears good interaction between filler and polymer, covering well the surface of CF fibers, as can be seen on SEM image (Figure 8b), and thus playing the role of an isolator. The permitivity of PP and $\mathrm{PP} / \mathrm{CF}(85 / 15)$ are order of magnitude higher due to the presence of interfacial polarization on the fiber/polymer interface. The highest conductivity is obtained for PP-10S/CF (85/15). 


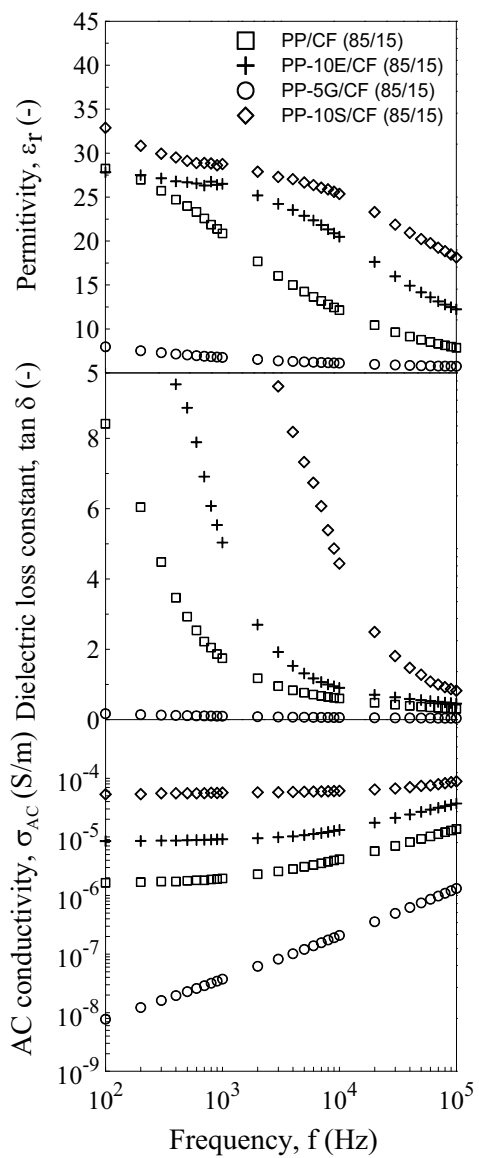

FIGURE 9. Permitivity, dielectric loss factor and AC conductivity as a function of frequency for $15 \mathrm{wt} \%$ carbon fiber filled pure and modified polypropylene.

Carbon fibers were also compounded into a polar thermoplastic matrix - polyamide 6 . As can be seen in the Figure 10, polyamide has good adhesion to filler, which is further improved after incorporating a modifier ethylene-ethyl acrylate-maleic anhydride (E-EA-MAH). The corresponding flow curves of PA based samples at 240 and $250^{\circ} \mathrm{C}$ are depicted in the Figure 11 . The viscosity of the PA matrix is enhanced with modification by E-EA-MAH at $240^{\circ} \mathrm{C}$. This trend is even more pronounced for $\mathrm{PA} / \mathrm{CF}$ and $\mathrm{PA}-5 \mathrm{E} / \mathrm{CF}$ composites were discrepancies at low shear rate region are clearly visible. At higher temperature $\left(250^{\circ} \mathrm{C}\right)$ the effect of PA modification is evident only for composites from $10^{-1}$ to $10^{0} \mathrm{~s}^{-1}$; with increasing of shear rate up to $10^{2} \mathrm{~s}^{-1}$ and higher viscosity of PA composites $(10 \mathrm{wt} \% \mathrm{CF})$ approaches that of pure PA. 


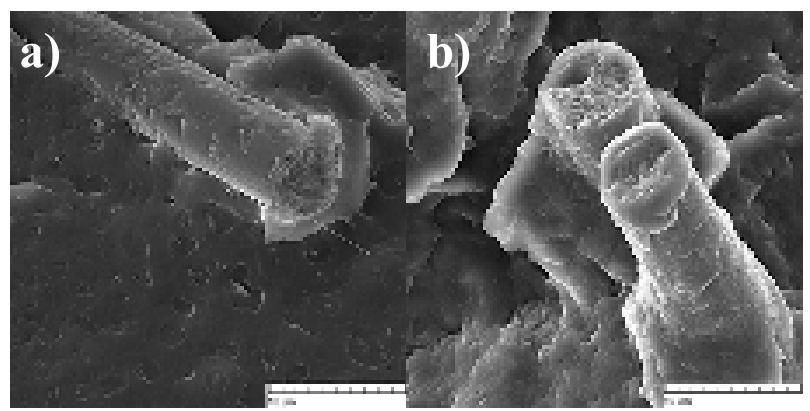

FIGURE 10. SEM micrographs of $10 \mathrm{wt} \%$ CF filled (a) unmodified and (b) E-EA-MAH modified polyamide 6 .

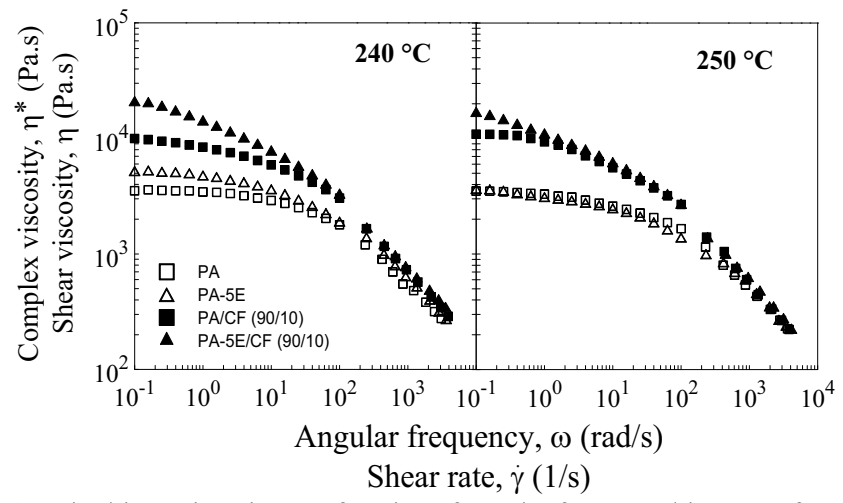

FIGURE 11. Complex/shear viscosity as a function of angular frequency/shear rate for $10 \mathrm{wt} \%$ carbon fiber filled and unfilled pure and modified polyamide 6 at different temperatures.

Finally, mechanical properties of PP and PA matrices and their composites with carbon fibers were measured and results are shown in the Tables 6 and 7. The Young's modulus of both PP and PA increased upon adding carbon fibers from $1200 \mathrm{MPa}$ (pure PP) to $4100 \mathrm{MPa}$ (PP-g-MA modified composite), i.e. increase of $340 \%$. Similarly, the Young's modulus of PA increases about $145 \%$ from $3100 \mathrm{MPa}$ (PA) to $4500 \mathrm{MPa}$ (E-EA-MAH modified composite). The same trend is obtained for three-point bending measurements; the increase is $310 \%$ and $165 \%$ for PP and PA based composites, respectively. Concerning impact strength, PP after modification with PP-g-MA and CF reinforcement displays reduction, while for PA based composites a slight increase in comparison to pure PA is attained. 
TABLE 6. Results of mechanical measurements of polypropylene (PP) based materials.

\begin{tabular}{|c|c|c|}
\hline & $\mathbf{P P}$ & PP-5G/CF (90/10) \\
\hline \multicolumn{3}{|l|}{ TENSILE TEST } \\
\hline Young's Modulus (MPa) & $1200.00 \pm 23.00$ & $4100.00 \pm 51.00$ \\
\hline Extension at Tensile Strength (mm) & $12.00 \pm 0.20$ & $6.20 \pm 0.10$ \\
\hline Tensile Stress at Tensile Strength (MPa) & $25.00 \pm 0.30$ & $47.00 \pm 0.40$ \\
\hline Tensile Strain at Tensile Strength (\%) & $11.00 \pm 0.20$ & $5.40 \pm 0.10$ \\
\hline Tensile Extension at Tensile Strength (mm) & $12.00 \pm 0.20$ & $6.20 \pm 0.10$ \\
\hline Yield Stress (MPa) & $25.00 \pm 0.30$ & $47.00 \pm 0.40$ \\
\hline Yield Strain (\%) & $10.00 \pm 0.40$ & $5.40 \pm 0.20$ \\
\hline Yield Extension (mm) & $12.00 \pm 0.40$ & $6.20 \pm 0.20$ \\
\hline \multicolumn{3}{|l|}{ THREE-POINT BENDING TEST } \\
\hline Young's Modulus (MPa) & $1100.00 \pm 13.00$ & $3400.00 \pm 29.00$ \\
\hline Flexural Strain at Tensile Strength (\%) & $8.00 \pm 0.30$ & $6.30 \pm 0.20$ \\
\hline Flexural Stress at Tensile Strength (MPa) & $36.00 \pm 0.30$ & $69.00 \pm 0.60$ \\
\hline Flexural Extension at Tensile Strength (mm) & $14.00 \pm 0.60$ & $11.00 \pm 0.30$ \\
\hline \multicolumn{3}{|l|}{ IMPACT TEST } \\
\hline Impact strength $\left(\mathrm{J} / \mathrm{cm}^{2}\right)$ & $6.00 \pm 0.10$ & $4.00 \pm 0.10$ \\
\hline
\end{tabular}

TABLE 7. Results of mechanical measurements of polyamide 6 (PA) based materials.

\begin{tabular}{|c|c|c|}
\hline & PA & PA-5E/CF (90/10) \\
\hline \multicolumn{3}{|l|}{ TENSILE TEST } \\
\hline Young's Modulus (MPa) & $3100.00 \pm 23.00$ & $4500.00 \pm 49.00$ \\
\hline Extension at Tensile Strength (mm) & $4.00 \pm 0.05$ & $7.50 \pm 0.20$ \\
\hline Tensile Stress at Tensile Strength (MPa) & $68.00 \pm 0.40$ & $78.00 \pm 0.70$ \\
\hline Tensile Strain at Tensile Strength (\%) & $3.50 \pm 0.05$ & $6.50 \pm 0.20$ \\
\hline Tensile Extension at Tensile Strength (mm) & $4.00 \pm 0.05$ & $7.50 \pm 0.20$ \\
\hline Yield Stress (MPa) & $68.00 \pm 0.40$ & $78.00 \pm 0.70$ \\
\hline Yield Strain (\%) & $3.00 \pm 0.07$ & $6.40 \pm 0.60$ \\
\hline Yield Extension (mm) & $4.00 \pm 0.08$ & $7.30 \pm 0.70$ \\
\hline \multicolumn{3}{|l|}{ THREE-POINT BENDING TEST } \\
\hline Young's Modulus (MPa) & $2500.00 \pm 15.00$ & $4100.00 \pm 54.00$ \\
\hline Flexural Strain at Tensile Strength (\%) & $6.00 \pm 0.20$ & $6.00 \pm 0.30$ \\
\hline Flexural Stress at Tensile Strength (MPa) & $96.00 \pm 0.70$ & $130.00 \pm 1.80$ \\
\hline Flexural Extension at Tensile Strength (mm) & $12.00 \pm 0.30$ & $11.00 \pm 0.50$ \\
\hline \multicolumn{3}{|l|}{ IMPACT TEST } \\
\hline Impact strength $\left(\mathrm{J} / \mathrm{cm}^{2}\right)$ & $12.00 \pm 0.20$ & $13.00 \pm 0.80$ \\
\hline
\end{tabular}

\section{CONCLUSION}

Recycled carbon fibers have been compounded with thermoplastic matrices based on pure and modified polypropylene and polyamide 6. Polypropylene grafted maleic anhydride (PP-g-MA), ethylene-ethyl acrylate-maleic anhydride (E-EA-MAH) and poly(styrene)-block-poly(ethylene-co-but-1-ene)-block-poly(styrene) (SEBS) were used as modifiers.

According to rheological behavior supported by morphological observation and electrical properties in both $\mathrm{AC}$ and $\mathrm{DC}$ fields, composite of carbon fiber and PP-g-MA modified polypropylene has been selected for further reusing of carbon fibers from aircraft waste. As a representative of non-polar thermoplastic matrix it has 
been also compared to $\mathrm{PA} / \mathrm{CF}$ composite. It has been verified that addition of carbon fibers into PP-g-MA modified polypropylene and E-EA-MAH modified polyamide 6 enhanced pronouncedly mechanical properties of pure PP and PA in terms of Young's modulus at tensile and three-point bending tests.

\section{ACKNOWLEDGEMENTS}

This work has been financially supported by the Ministry of Education, Youth and Sports of the Czech Republic (project No. MSM 7088352101). The authors thank the Aeronautical Research and Test Institute (VZLÚ), Prague, Czech Republic for supplying of recycled carbon fibers.

\section{REFERENCES}

1. O. S. Carneiro and J. M. Maia, Polym. Compos. 21, 970-977 (2000).

2. T. McNally, P. Boyd, C. McClory, D. Bien, I. Moore, B. Millar, J. Davidson and T. Carroll, J. Appl. Polym. Sci. 107, 2015-2021 (2008).

3. C. E. Kouparitsas, C. N. Kartalis, P. C. Varelidis, C. J. Tsenoglou and C. D. Papaspyrides, Polym. Compos. 23, 682-689 (2002).

4. A. Markov, B. Fiedler and K. Schulte, Composites Part A 37, 1390-1395 (2006).

5. M. Valeš and B. Štekner, Czech aerospace 3, 12-13 (2006).

6. B. Hausnerová, N. Honková, A. Lengálová, T. Kitano and P. Sáha, Polymer Science Series A 48, 951-960 (2006).

7. P. Järvelä, S. Li and P. J. Järvelä, Appl. Polym. Sci. 62, 813-826 (1996).

8. S. Li, P. Järvelä and P. J. Järvelä, Appl. Polym. Sci. 71, 1641-1648 (1999).

9. P. L. Ma and B. D. Favis, Polym. Eng. Sci. 42, 1976-1989 (2002).

10. N. Mnif, V. Massardier-Nageotte and M. J. Jaziri, Appl. Polym. Sci. 104, 3220-3227 (2007).

11. K. Zribi, K. Elleuch, J. F. Feller, A. Bourmaud and B. Elleuch, Polym. Eng. Sci. 47, 1768-1776 (2007).

12. F. Stricker and R. Mülhaupt, Polym. Eng. Sci. 38, 1463-1470 (1998).

13. S. Setz, F. Stricker, J. Kressler, T. Duschek and R. Mülhaupt, J. Appl. Polym. Sci. 59, 1117-1128 (1996).

14. F. Stricker, Y. Thomann and R. Mülhaupt, J. Appl. Polym. Sci. 68, 1891-1901 (1998). 
Copyright of AIP Conference Proceedings is the property of American Institute of Physics and its content may not be copied or emailed to multiple sites or posted to a listserv without the copyright holder's express written permission. However, users may print, download, or email articles for individual use. 